\title{
The Differences in the Speakers' Perception on Advice Strategies between Iranian Males and Females
}

\author{
Marzieh Rezaie \\ Shahreza Branch, Islamic Azad University, Iran \\ Email: marziehrezaie83@yahoo.com
}

Doi:10.5901/mjss.2014.v5n20p2417

\begin{abstract}
This research was conducted to examine the differences in the speakers' perception on advice strategies between Iranian males and females. 56 Persian native speakers from various academic fields participated in this study. 28of them were male and the rest were female. Chuns' questionnaire was modified and used in this study. This questionnaire was based on Brown and Levinson's (1987) politeness strategies. The data was analyzed through calculating frequencies, percentages and chisquares. The results of this study showed that in offering serious advice to a professor whom they are very close with Iranian males significantly used more bald on record than females and it may indicate that they considered a very close professor as an insider of "we group".
\end{abstract}

Keywords: politeness strategies, advice strategies, face

\section{Introduction}

Politeness is "one of the constraints on human interaction, whose purpose is to consider others' feelings, establish levels of mutual comfort, and promote rapport" (Hill et al. ,1986;p. 349).According to Brown and Levinson's (1987), politeness is related to awareness of others face wants. Face is a term which is used by Goffman for the first time. According to him, face is a" positive value a person claims for himself by the line others assume he has taken a personal contact" (Goffman; 19999, p.306, orig, 1955; as cited in Bloor and Bloor). Brown and Levinson's (1987) referred to face as public self-image that a person assumes for himself/herself. Face is something that can be lost, maintained and enhanced.

Brown and Levinson (1987) mentioned five strategies for politeness. The first one is on-record performance of FTAs without redressive actions which is called bald on record, the second and third ones are positive politeness and negative politeness strategies which are related to on-record performance of FTAs with redressive action, the fourth one is off record, and the fifth one is not doing face threatening acts.

In bald on record strategy, speaker doesn't do any acts to minimize threats to his/her hearer face. Positive politeness is related to maintaining the positive face of the hearer, (i.e., the positive self-image that hearer considered for her/himself). Negative politeness, on the other hand, is related to satisfying the hearer's negative face, (i.e., hearer desire to be free from imposition). And in off record strategies, speaker uses indirect politeness strategies such as hint.

Different factors can affect the use of politeness strategies. Brown and Levinson (1987) mentioned three basic sociological factors that are which are important in determining the level of politeness. They are social distance, power and rank of imposition.

Wolfson(1989; as cited in Salmani Nodoushan,2008) also contents that, people are more polite to1) those who had higher status than them or are more powerful than them; and 2) to those who had socially distant relationships with them ; and they are also more polite in the situations when there are serious threat to their interlocutors' faces.

Scollon and Scollon (1995) mentioned three politeness systems including deference politeness system, solidarity politeness system and hierarchical politeness system which are differentiated from each other according to power difference $(+P$ or $-P)$ and on the social distance $(+D$ or $-D)$ which exist between speaker and hearer.

People should pay attention to politeness issues when they want to use different speech acts. Advice is a kind of speech act which is done for giving information, recommendations, or suggesting different actions to the recipients (Advice, 2010). It should be done carefully, because it may threaten the recipients' negative face and people mostly do not like to receive advice (Goldsmith, 2004; as cited in Kouper, 2010). Therefore, speakers may use some strategies such as indirectness, hedging, and other forms of politeness to limit the threat to hearer's face (Brown \& Levinson, 1987).

Due to the importance of this issue, this study aimed to explore the differences in the speakers' perception on 
advice strategies between Iranian males and females?

\section{Literature Review}

Different studies have been done on politeness. Marti (2006) explored the relation between indirectness and politeness in the speech act of request. The participants of this study were Turkish-German bilinguals and Turkish monolinguals. The results showed that there is relation between indirectness and politeness but this is not linear relation.

Fe'lix-Brasdefer(2006) studied on politeness during refusal interactions among male speakers of Mexican Spanish in these three politeness systems: solidarity, deference, and hierarchy (Scollon and Scollon, 2001). The results showed that social factors such as power (+P or _P) and distance (+D or _D) were important factors in determining the level of politeness in refusal interactions.

Jansen and Janssen (2010) studied on the effect of positive politeness strategies in business letters. The results showed that among the politeness strategies "giving reasons" was positively effective but "giving compliments" or "asserting knowledge"' hadn't any effects on the evaluation of the business letters .

Stephan and Liberman (2010) tried to find whether politeness and psychological distance are related. The results of their study showed in the cases of abstract construal, temporal distance, and spatial distance politeness would be increased.

Hinkel (1997) studied on appropriateness of advice provided by Chinese and American students. The results showed that NSs used mainly fewer direct or hedged advices than the Chinese students.

Goldsmith (2000) explored whether sequential placement of advice has any effects on limiting face threat. The results showed that it has a significant effect on mitigating the face threat.

The results of Hummert and Mazloff 's (2001) study on older adults' responses to patronizing advice showed that the participants responded at least in five forms including appreciative, assertive, passive, ignoring, condescending to patronizing advice which can ranked from highly polite to polite to impolite. The results also showed patronizing advice is legitimate in hospital context.

MacGeorge , Feng, Butler, and Budarz (2004) investigated the effect of advice content characteristics, face work, and support-seekers' receptiveness to advice on advice message quality evaluations and advice outcomes. According to their findings, face work had a large and important effect on facilitation of coping (one of content characteristics).

Feng(2009) was tested an integrated model of advice giving in supportive interactions. The results of Feng's study showed that if a person follows the sequence of emotional support, problem inquiry and analysis and advice for offering advice, the advice will be evaluated more positively by the recipient than if he/she doesn't follow this sequence.

The results of Harrison and Barlow's (2009) study on politeness strategies and advice-giving in an online arthritis workshop showed that participants use different advice-giving strategies. For example, they used imperative forms for giving direct advice and declarative statements and mitigated forms for giving indirect advice.

Kouper (2010) explored the patterns and structures of peer advice interactions in a Live Journal community. The results of this study showed that giving and receiving advice is a common type of social interaction in this community. Moreover, messages which are used for giving and soliciting advice have their own specific structures and pragmatic features.

\section{Research Methodology}

\subsection{Participants}

56 Persian native speakers from various academic fields participated in this study. 28 of them were male and the rest were female. Their ages were from 20 to 30.

\subsection{Instrument}

Chuns' questionnaire was modified and used in this study. This questionnaire includes 8 situations. For each situation, there were considered four advice strategies including bald on record, on record with redress, off record in term of hint and not doing face threatening acts which were adapted from Brown and Levinson's (1987) politeness strategies. Each situation was based on one of these themes serious advice or trivial advice. Other variables were distance (close (-D) and not so close $(+D)$ relations) and power (vertical $(+P)$ and horizontal $(=P)$ relation). A clear Instruction for completing the questionnaire was written in this questionnaire. 


\subsection{Procedure}

The written Persian questionnaire was distributed to 56 Persian native speakers including males and females from various academic fields. This questionnaire was given to volunteers and they were asked to fill out the questionnaire anonymously.

Then the collected data was analyzed through calculating frequencies and percentages and chi-squares.

\section{Findings and Discussion}

Table 1. Frequencies of Advice Strategies Selected by Iranian Girls

\begin{tabular}{|c|c|c|c|c|c|c|c|c|c|}
\hline Items & & & & & & Bald on record & On record with redress & Off record in term of hint & Not doing FTAs \\
\hline 1 & Frequencies & \begin{tabular}{|l|l}
3 & 1 \\
\end{tabular} & \begin{tabular}{l|l}
16 & 6 \\
\end{tabular} & 3 & Percentages & 10.71429 & 57.14286 & 21.42857 & 10.71429 \\
\hline 2 & & \begin{tabular}{|l|l}
0 & 1 \\
\end{tabular} & 105 & 13 & & 0 & 35.71429 & 17.85714 & 46.42857 \\
\hline 3 & & 22 & \begin{tabular}{l|l}
6 & 0 \\
\end{tabular} & 0 & & 78.57143 & 21.42857 & 0 & 0 \\
\hline 4 & & \begin{tabular}{|l|l}
2 & 1 \\
\end{tabular} & \begin{tabular}{l|l}
13 & 7 \\
\end{tabular} & 6 & & 7.142857 & 46.42857 & 25 & 21.42857 \\
\hline 5 & & 022 & \begin{tabular}{l|l}
235 \\
\end{tabular} & 0 & & 0 & 82.14286 & 17.85714 & 0 \\
\hline 6 & & $\begin{array}{ll}0 \\
0\end{array}$ & \begin{tabular}{l|l}
2 & 1 \\
\end{tabular} & 7 & & 0 & 7.142857 & 67.85714 & 25 \\
\hline 7 & & \begin{tabular}{|l|l}
8 & 1 \\
\end{tabular} & 191 & 0 & & 28.57143 & 67.85714 & 3.571429 & 0 \\
\hline 8 & & \begin{tabular}{|l|l}
4 & 1 \\
\end{tabular} & 125 & 7 & & 14.28571 & 42.85714 & 17.85714 & 25 \\
\hline
\end{tabular}

Table 2. Frequencies of Advice Strategies Selected by Iranian Boy

\begin{tabular}{|c|c|c|c|c|c|c|c|c|c|c|}
\hline Items & & & & & & & Bald on record & On record with redress & Off record in term of hint & Not doing FTAs \\
\hline 1 & Frequencies & 12 & 13 & 1 & 2 & Percentages & 42.85714 & 46.42857 & 3.571429 & 7.142857 \\
\hline 2 & & 1 & 9 & 6 & 12 & & 3.571429 & 32.14286 & 21.42857 & 42.85714 \\
\hline 3 & & 24 & 3 & 1 & 0 & & 85.71429 & 10.71429 & 3.571429 & 0 \\
\hline 4 & & 8 & 12 & 6 & 2 & & 28.57143 & 42.85714 & 21.42857 & 7.142857 \\
\hline 5 & 1 & 17 & 8 & 2 & & 3.571429 & 60.71429 & 28.57143 & 7.142857 \\
\hline 6 & 0 & 0 & 6 & 13 & 9 & & 0 & 21.42857 & 46.42857 & 32.14286 \\
\hline 7 & 13 & 15 & 0 & 0 & & 46.42857 & 53.57143 & 0 & 0 \\
\hline 8 & & 4 & 13 & 6 & 5 & & 14.28571 & 46.42857 & 21.42857 & 17.85714 \\
\hline
\end{tabular}

As it can be seen in these tables, in situation1 (offering serious advice to a professors whom they are very close with), Iranian males (42.85) significantly used more bald on record than females (10.71). Bald on record is the least polite form in Brown and Levinson theory. But in this situation, it may not show that they were impolite, it may show that they considered a very close professor as an insider of "we group". Moreover, in situation 1, both Iranian girls (57/14\%) and boys (46/42) mostly used on record with redress.

In situation 2(offering serious advice to a professor whom they are not very close with) both Iranian girls (46.42) and boys (42.85) mostly didn't do face threatening acts.

In situation 3(offering serious advice to a friend whom they are very close with) both Iranian girls (78.57) and boys (85.71) mostly used bold on record.

In situation 4 (offering serious advice to a friend whom they are not very close with) both Iranian girls (46.42) and boys (42.85) mostly used on record with redress.

In situation 5(offering trivial advice to a professor whom they are very close with) both Iranian girls (82.14) and boys (60.71) mostly used on record with redress.

In situation 6(offering trivial advice to a professor whom they are not very close with) both Iranian girls (67.85) and boys (46.42) mostly used off record in term of hint.

In situation 7 (offering trivial advice to a friend whom they are very close with) both Iranian girls (67.85) and boys (53.57) mostly used on record with redress.

And in situation 8 (offering trivial advice to a friend whom they are not very close with) both Iranian girls (42.85) and boys (46.42) mostly used on record with redress. 
Table 3. Chi-square Values of the Impact of $D$ on Advice Strategies Used by Iranian Males and Females

\begin{tabular}{|l|c|c|c|c|}
\hline \multirow{2}{*}{} & \multicolumn{2}{|c|}{ Serious advice } & \multicolumn{3}{c|}{ Trivial advice } & (S7-S8) friend \\
\cline { 2 - 5 } & (S1-S2) professor & (S3-S4) friend & (S5-S6) professor & $/ 488$ \\
\hline Male & $0 / 122$ & $0 / 415$ & $\underline{0 / 042}$ & $0 / 389$ \\
\hline Female & $0 / 072$ & $0 / 670$ & $0 / 473$ & \multicolumn{3}{|c|}{} \\
\hline
\end{tabular}

For determining the effect of distance on advice strategies, the effects of other variables including power, gender, and the type of advice have been controlled. In the situations in which males offered trivial advice to their professors, the effect of distance was significant $(\mathrm{p}=0 / 042<0 / 05)$.

Table 4.Chi-square Values of the Impact of P on Advice Strategies Used by Iranian Males and Females

\begin{tabular}{|l|c|c|c|c|}
\hline \multirow{2}{*}{} & \multicolumn{2}{|c|}{ Serious advice } & \multicolumn{3}{c|}{ Trivial advice } \\
\cline { 2 - 5 } & (S1-S3) close & (S2-S4) not close & (S5-S7) close & (S6-S8)not close \\
\hline Male & $0 / 074$ & $0 / 347$ & $\underline{0 / 016}$ & $0 / 266$ \\
\hline Female & $0 / 238$ & $0 / 337$ & $0 / 597$ & $0 / 601$ \\
\hline
\end{tabular}

This time for determining the effect of power on advice strategies, the effects of other variables including distance, gender, and the type of advice had been controlled. As this table shows, in the situation in which males offer trivial advice to their close interlocutors $(p=0 / 016</ 05)$ the effect of power was significant.

Table 5.Chi-square Values of the Impact of Seriousness of Advice on Politeness Strategies Used by Iranian Males and Females

\begin{tabular}{|l|c|c|c|c|}
\hline \multirow{2}{*}{} & \multicolumn{2}{|c|}{ Serious/ trivial advice } & \multicolumn{3}{c|}{ Serious /trivial advice } \\
\cline { 2 - 5 } & Close professor (S1-S5) & Not close professor (S2-S6) & Close friend (S3-S7) & Not close friend (S4-S8) \\
\hline Male & $0 / 295$ & $0 / 154$ & $0 / 550$ & $0 / 246$ \\
\hline Female & $0 / 824$ & $\underline{0 / 056}$ & $0 / 801$ & $0 / 299$ \\
\hline
\end{tabular}

As this table shows, in the situation in which females offer advice to their professors whom they had not close relationships, the effect of type of advice was significant $(p=0 / 05$, the effects of other variables including distance, gender, and power had been controlled).

\section{Concluding Remarks}

Politeness is one of the necessities of human interaction. Therefore people may use different strategies for politeness such as bald on record, positive politeness, negative politeness strategies, off record and not doing face threatening acts to consider others' face wants (Brown and Levinson, 1987).

Moreover, different factors can affect the use of politeness strategies such as social distance, power and rank of imposition (Brown and Levinson, 1987).

The results of the analyses and discussions indicated that in situation1 (offering serious advice to a professor professors whom they are very close with), Iranian males significantly used more bald on record than females and it may show that they considered a very close professor as an insider of "we group". However, in other situations, there were some similarities regarding the use of advice strategies.

Furthermore, in the situations in which males offered trivial advice to their professors, the effect of distance was significant .Also, in the situation in which males offer trivial advice to their close interlocutors, the effect of power was significant. And, in the situation in which females offer advice to their professors whom they had not close relationships, the effect of type of advice was significant.

Other researchers also had different findings regarding the use of politeness strategies among males and females. For example, Hobbs (2003) studied on the use of politeness strategies in males' and females' voice mail messages. The results showed that males and females' used the equal politeness markers in their voice messages in a legal setting.

Al-Marrani and Sazalie(2010) also investigated the use of polite request strategies in male- male interactions and male-female interactions among male speakers of Yemeni Arabic. The results showed they were highly direct in male- 
male interactions and this is because of their close relationships and solidarity but they were highly indirect in malefemale interactions and this is because of their religious beliefs.

As the results of these studies show there were some similarities and differences regarding the uses of politeness strategies among males and females.

\section{References}

Al-Marrani, Y., M., A, \& Sazalie, A., B (2010), Polite request strategies by male speakers of Yemeni Arabic in male-male interaction and male-female interaction. The International Journal of Language Society and Culture 30, 63-80.

Brown, P., \& Levinson, S. (1978).Universals in language usage: politeness phenomena. In E.N. Goody (Ed.), Questions and politeness: Strategies in social interaction (pp.56-289). Cambridge: Cambridge University Press.

Brown, P., \& Levinson, S. (1987). Politeness: Some universals in language usage. Cambridge, U.K.: Cambridge University Press.

Fe'lix-Brasdefer, J., C. (2006). Linguistic politeness in Mexico: Refusal strategies among male speakers of Mexican Spanish. Journal of Pragmatics 38, 2158-2187.

Feng, B. (2009). Testing an integrated model of advice giving in supportive interactions. Human Communication Research, 35, 115-129

Goldsmith, D. (2000). Soliciting advice: The role of sequential placement in mitigating face threat. Communication Monograph, 67(1), 119.

Harrison, S., \& Barlow, J. (2009). Politeness strategies and advice-giving in an online arthritis workshop. Journal of Politeness Research: Language, Behavior, Culture, 5(1), 93-111.

Hill, B., Ide, S., Ikuta, S., Kawasaki, A., \& Ogino, T. (1986).Universals of linguistic politeness: Quantitative evidence from Japanese and American English. Journal of Pragmatics, 10, 347-71.

Hinkel, E. (1997). Appropriateness of advice: DCT and multiple choice data. Applied Linguistics, 18(1), 1-26.

Hobbs, P. (2003). The medium is the message: Politeness strategies in men's and women's voice mail messages. Journal of Pragmatics $35,243-262$.

Hummert, M. L., \& Mazloff, D. C. (2001). Older adults' responses to patronizing advice: Balancing politeness and identity in context. Journal of Language and Social Psychology, 20, 168-196.

Jansen, F. \& Janssen, D (2010). Effects of positive politeness strategies in business letters. Journal of Pragmatics 42, 2531-2548.

Kouper, I. (2010).The pragmatics of peer advice in a live journal community. Language @ Internet, 7(1),1-21.

MacGeorge, E. L., Feng, B., Butler, G. L., \& Budarz, S. K. (2004). Understanding advice in supportive interactions: Beyond the facework and message evaluation paradigm. Human Communication Research, 30(1), 42-70.

Marti, L. (2006). Indirectness and politeness in Turkish-German bilingual and Turkish monolingual requests. Journal of Pragmatics, 38 , 1836-1869.

Salmani Nodoushan, M., A. (2008).Persian requests: Redress of face through indirectness. Iranian Journal of Language Studies,2(3),258-280.

Stephan, E. \&Liberman, N. (2010). Politeness and psychological distance: A Construal level perspective. Journal of Personality and Social Psychology 98(2), 268-280

\section{Appendix: Questionnaire}

Situation 1: [+P/-D] serious advice

A professor whom you are very close with always drives very fast. You always thought that he shouldn't drive very fast. Now you see him and notice that he wants to drive. What do you think would be appropriate to say in this situation?

A. You shouldn't drive very fast. It is dangerous.

B. I think it's better to drive at suitable speeds. I've heard that diving at high speeds causes bad accidents.

C. I've heard that diving at high speeds causes bad accidents.

D. Nothing

Situation 2: $[+p /+D]$ serious advice

A professor whom you are not very close with always drives very fast. You often thought that he shouldn't drive very fast. Now you see him and notice that he wants to drive. What do you think would be appropriate to say in this situation?

A. You shouldn't drive very fast. It is dangerous.

B. I think it's better to drive at suitable speeds. I've heard that diving at high speeds causes bad accidents.

C. I've heard that diving at high speeds causes bad accidents.

D. Nothing

Situation 3: $[=p /-D]$ serious advice

A friend whom you are very close with always drives very fast. You always thought that he shouldn't drive very fast. Now you see him and notice that he wants to drive. What do you think would be appropriate to say in this situation?

A. You shouldn't drive very fast. It is dangerous.

B. I think it's better to drive at suitable speeds. I've heard that diving at high speeds causes bad accidents.

C. I've heard that diving at high speeds causes bad accidents. 
D. Nothing

Situation 4: $[=p /+D]$ serious advice

A freind whom you are not very close with always drives very fast. You often thought that he shouldn't drive very fast. Now you see him and notice that he wants to drive. What do you think would be appropriate to say in this situation?

A. You shouldn't drive very fast. It is dangerous.

B. I think it's better to drive at suitable speeds. I've heard that diving at high speeds causes bad accidents.

C. I've heard that diving at high speeds causes bad accidents.

D. Nothing

Situation 5: $[+\mathrm{p} /-\mathrm{D}]$ trivial advice

A professor whom you are very close with has been a widely known as a competent and brilliant scholar. However, he doesn't ask his students to do some researches and doesn't consider any points for doing researches. How would you advise to him in this situation?

A. You should ask his students to do some researches and consider some points for doing researches!

B. Why don't you ask your students to do some researches and consider some points for doing researches!

C. I've heard that in more developed countries, professors pay attention a lot to students' researches when they want to evaluate them.

D. Nothing

Situation 6: $[+p /+D]$ trivial advice

A professor whom you are not very close with has been a widely known as a competent and brilliant scholar. However, he doesn't ask his students to do some researches and doesn't consider any points for doing researches. How would you advise to him in this situation?

A. You should ask his students to do some researches and consider some points for doing researches!

B. Why don't you ask your students to do some researches and consider some points for doing researches!

C. I've heard that in more developed countries, professors pay attention a lot to students' researches when they want to evaluate them.

D. Nothing

Situation 7: [=p/-D] trivial advice

You are in a live class discussion with your classmates. Your friend who is very close with you isn't really participating in the discussion. She/he is very smart but quiet and a little shy, so she/he is probably worried of speaking out wrong opinions. You always felt that she/he should be more active and show her/his talents. You are going to give her/him an advice how would you say to her/him?

A. Speak out and participate!

B. You're such a smart and talent person, what are you worried about! Speak out and be participative!

C. You're not really interested in this class, are you?

D. Nothing.

Situation 8: [=p/+D] trivial advice

You are in a live class discussion with your classmates. Your friend who is not very close with you isn't really participating in the discussion. She/he is very smart but quiet and a little shy, so she/he is probably worried of speaking out wrong opinions. You always felt that she/he should be more active and show her/his talents. You are going to give her/him an advice how would you say to her/him?

A. Speak out and participate!

B. You're such a smart and talent person, what are you worried about! Speak out and be participative!

C. You're not really interested in this class, are you?

D. Nothing. 